\title{
TENSILE STRENGTH OF Zr-2.5Nb PRESSURE TUBES: A STATISTICAL STUDY
}

\author{
Priti Kotak Shah $^{1}$, J.S. Dubey ${ }^{1}$, D. Datta ${ }^{1}$, R.S. Shriwastaw ${ }^{1}$, B. N. Rath $^{1}$, R.N. $\operatorname{Singh}^{1}$ and S. $^{2}$ \\ Anantharaman ${ }^{2}$ \\ ${ }^{1}$ Senior Scientist, Bhabha Atomic Research Centre, India \\ ${ }^{2} \mathrm{Head}$, Post Irradiation Examination Division, Bhabha Atomic Research Centre, Mumbai, India
}

\begin{abstract}
In order to get an idea of the statistical variation in the tensile properties of the double-melted as well as quadruple melted $\mathrm{Zr}-2.5 \mathrm{Nb}$ pressure tubes (PTs) and also the variation in tensile properties between the two ends of the pressure tubes, tension tests were carried out on around fifty pressure tube off-cuts. Before installation in the reactor small rings called off-cuts are cut from both ends of the pressure tubes. Longitudinal and transverse tensile specimens were prepared from these off-cuts of pressure tubes of double-melted and quadruple melted types. For quadruple melted pressure tubes the specimens were tested from both front-end and back-end off-cuts.

Miniature flat tensile specimens having $1.8 \mathrm{~mm}$ width and $1.5 \mathrm{~mm}$ thickness and $7.6 \mathrm{~mm}$ gauge length were prepared from the pressure tube off-cuts without any flattening treatment. Tension tests were carried out in a screw-driven machine at room temperature.

In general the transverse specimens showed higher yield strength (YS) and ultimate tensile strength (UTS) compared to the longitudinal specimens. Transverse specimens showed less strain hardening compared to the longitudinal specimens. The axial specimens showed higher uniform (UE) and total elongation (TE) compared to the transverse specimens. Not much variation was found between front-end and back-end of the pressure tubes. Double-melted pressure tubes showed relatively higher strength and lower elongation and larger standard deviation compared to the quadruple melted pressure tubes.
\end{abstract}

\section{INTRODUCTION}

The manufacturing route of $\mathrm{Zr}-2.5 \mathrm{Nb}$ pressure tubes, used in Indian Pressurised Heavy Water Reactors (PHWRs) has been changed from cold drawing to two stage pilgering with intermediate annealing treatment (Srivastava et al. 1995, Singh et al. 2002) from double melted (DM) ingot to quadruple melted (QM) ingot,. Low hydrogen and trace impurities (like chlorine, phosphorus which are mainly responsible for the lower fracture toughness of the pressure tube) are achieved by quadruple melting of the ingots (Ganguly 2002). Differences in the ingot from which pressure tubes are fabricated and also variations in the fabrication parameters within the limits of specification may lead to tube to tube variation in the microstructure and texture. The extrusion process has a significant effect on the pressure tube properties, in particular, the mechanical strength and micro-structural features important for deformation, such as basal pole texture and grain shape and size (Rodgers et al. 2008). Even the differences in the extrusion temperature along the length of the tube lead to variations in grain size, dislocation density along the length of the pressure tube. These, in turn, may lead to differences in mechanical properties from tube to tube as well as from one end of the tube to the other end of the tube. Before installing the pressure tubes into the reactor, rings of material (off-cuts) are removed from the front and back end of each pressure tube, this distinction referring to the end emerging first and last, respectively, from the extrusion press (Davies et al.1995). In general, strength increases from front-end to back-end of the tube (Dureja et al. 2011). Mechanical property of $\mathrm{Zr}-2.5 \mathrm{Nb}$ is also different in different 
direction. Other than anisotropic crystal structure, the texture developed during fabrication also leads to differences in tensile property in the axial and transverse directions of the pressure tubes.

The objective of the present experiment was to study the statistical variation in:

i. tensile properties in axial and transverse direction for a number of Indian $\mathrm{Zr}-2.5 \mathrm{Nb}$ PHWR pressure tubes.

ii. distribution of tensile properties of double-melted and quadruple-melted pressure tubes.

iii. tube to tube variation in tensile properties for the front-end off-cut of quadruple-melted PTs

iv. tensile properties at the front-end and back-end of the quadruple-melted pressure tube.

\section{EXPERIMENTAL}

\section{Material}

The front-end and back-end off-cuts used in the present study are from the quadruple melted $\mathrm{Zr}$ $2.5 \mathrm{Nb}$ pressure tubes (QM-PTs). There were total 32 off-cut pieces from 16 pressure tubes i.e from each of the 16 pressure tube there was one front-end off-cut and one back-end off-cut. The location of frontend off-cut and one back-end off-cut in a pressure tube is shown in fig.1. Tension test was also carried out on the 15 off-cuts from pressure tubes of double-melted (DM-PTs) origin. The specified chemical composition and tensile properties for the Indian PHWR pressure tubes is given in table $1 \&$ table 2 respectively. KAPS-2 is the first Indian PHWR which started using $\mathrm{Zr}-2.5 \mathrm{Nb}$ pressure tubes instead of Zircaloy-2 pressure tubes. RAPS-2 is the first reactor in which all the Zircaloy-2 pressure tubes were replaced with quadruple-melted $\mathrm{Zr}-2.5 \mathrm{Nb}$ pressure tubes during en-mass coolant channel replacement (EMCCR).

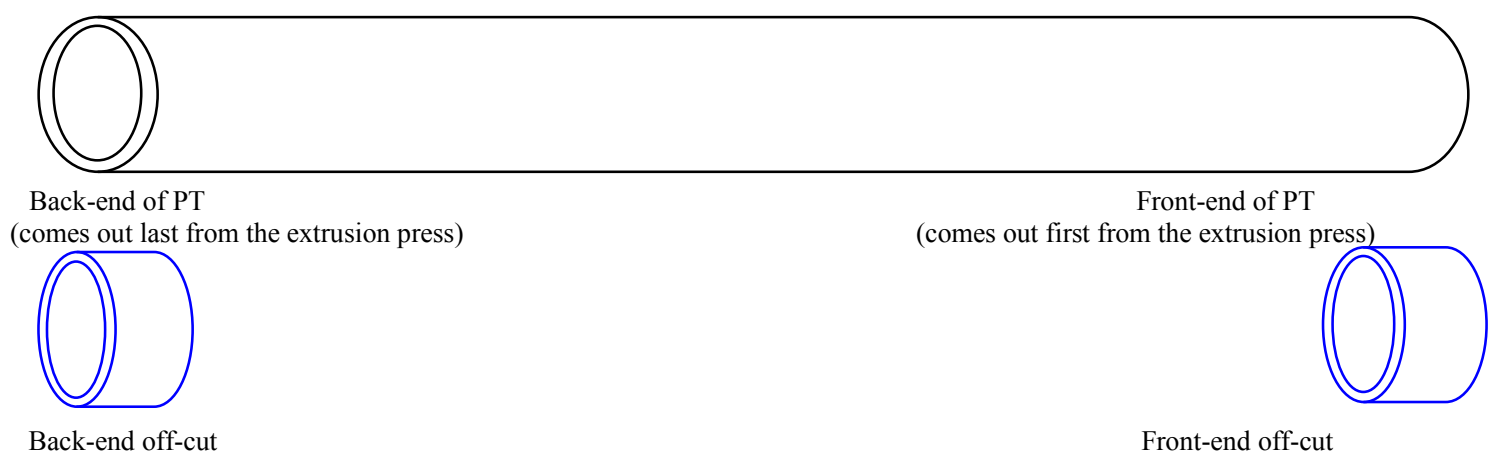

Fig. 1: Front-end off-cut and one back-end off-cut in a pressure tube

Table 1: Major specified chemical composition of $\mathrm{Zr}-2.5 \mathrm{Nb}$ pressure tubes (Kapoor et al. 1999)

\begin{tabular}{|l|c|c|}
\hline \multirow{2}{*}{ Elements alloyed to Zirconium } & \multicolumn{2}{|c|}{ Specified value } \\
\cline { 2 - 3 } & Double-melted & Quadruple-melted \\
\hline Niobium, \% & $2.4-2.8$ & $2.4-2.8$ \\
\hline Oxygen, ppm & $900-1300$ & $900-1300$ \\
\hline Iron, ppm & $1500 \mathrm{max}$ & $650 \mathrm{max}$ \\
\hline Hydrogen, ppm & $25 \max$ & 5 max \\
\hline Chlorine, ppm & $\ldots$ & $0.5 \max$ \\
\hline Phosphorous, ppm & $\ldots$ & 10 max \\
\hline
\end{tabular}


Table 2: Specified longitudinal tensile properties for the Indian pressure tubes (Ganguly 2002)

\begin{tabular}{|l|c|c|}
\hline \multirow{2}{*}{ Properties } & \multicolumn{2}{|c|}{$\mathrm{Zr}-2.5 \mathrm{Nb}$} \\
\cline { 2 - 3 } & Room Temp. & $300^{\circ} \mathrm{C}$ \\
\hline Ultimate tensile strength $(\mathrm{MPa})$ & - & $\geq 462$ \\
\hline $0.2 \%$ Yield strength $(\mathrm{MPa})$ & $\leq 586$ & $\geq 324$ \\
\hline Percentage elongation & - & $\geq 14.0$ \\
\hline
\end{tabular}

\section{Tension Test}

As the maximum length of the off-cut available was $35 \mathrm{~mm}$, miniature flat tensile specimen test was selected for mechanical property evaluation of the off-cuts from different pressure tubes. Flat longitudinal and transverse tensile specimens as shown in fig. 2 below were prepared from pressure tubes. Longitudinal (or axial) and transverse (or circumferential) specimens are termed as the ones taken from the longitudinal (i.e. axial) and transverse (i.e. circumferential) direction of the pressure tube with the tensile axis being parallel either to the longitudinal or to the transverse directions of the pressure tube, respectively. Tensile specimens were having $1.8 \mathrm{~mm}$ width and $1.5 \mathrm{~mm}$ thickness and $7.6 \mathrm{~mm}$ gauge length. Specimens of both orientations were prepared without any flattening treatment. Wire cut EDM was used for tensile specimen preparation.

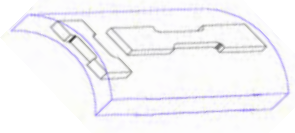

Fig.2: Type of specimens (transverse and longitudinal) prepared from off-cuts

The shoulder girder type tensile test jig was used to put the specimen on the grip easily. Tension tests were carried out at room temperature in a $100 \mathrm{KN}$ capacity screw driven universal testing machine (UTM). The crosshead speed during the testing was $0.25 \mathrm{~mm} / \mathrm{min}$. Tests were conducted in air atmosphere.

\section{RESULT AND DISCUSSION}

The off-cuts used in the present study were from double-melted and quadruple melted $\mathrm{Zr}-2.5 \mathrm{Nb}$ pressure tubes. These pressure tubes are produced by hot extrusion followed by two stage cold pilgering with intermediate annealing. The fabrication process develops two phase microstructure of strongly textured alpha-grain and a grain boundary network of beta-phase. The alpha-grains have a hexagonal close packed (hcp) crystal structure. Evolution of texture takes place during hot extrusion process and subsequent pilgering elongates the alpha-grains and thus affect the grain aspect ratio. Batch to batch variation in chemical composition and hot working process parameters within the limits of specification cause the variation in micro-structure, texture and mechanical properties. During hot extrusion, the microstructure and texture of the leading end to the trailing end vary due to the variation in the hot working temperature (Srivastava et al. 1995). The crystallographic texture, grain size and grain aspect ratio, dislocation density developed during fabrication of pressure tube govern mechanical properties. In order to achieve improved in-reactor performance in terms of dimensional changes, it is desirable to produce pressure tubes with uniform microstructure, texture and mechanical properties. This is ensured 
by adopting manufacturing practice which ensures production of pressure tubes with variation in the microstructural parameters and mechanical properties within a narrow band.

\section{Longitudinal/Axial And Transverse Tensile Properties:}

A typical stress-strain plot obtained in room temperature testing of axial and transverse specimen for the $\mathrm{Zr}-2.5 \mathrm{Nb}$ alloy pressure tube material manufactured by double/quadruple melting is shown in fig. 3. Typical tested specimens of longitudinal and transverse orientation is shown in fig. 4. The effect of orientation on the fracture features can be clearly seen in this figure. For the axial samples the shear failure is inclined to radial direction whereas for the transverse samples the shear failure is inclined to transverse direction.

In general the transverse specimens showed higher yield strength (YS) and ultimate tensile strength (UTS) compared to the longitudinal specimens (Shewfelt 1984). The tensile strength of the transverse specimens is relatively closer to the yield strength compared to that in the axial specimens. That means transverse specimens showed less strain hardening compared to the longitudinal specimens. The uniform and total elongation also depends on specimen orientation. The axial specimens showed higher uniform and total elongation compared to the transverse specimens.

Plastic deformation occurs in $\mathrm{Zr}-2.5 \mathrm{Nb}$ occurs by dislocation glide upon either prismatic $\{1010\}$ $<1210>$ or pyramidal $\{1011\}<1123>$ slip system (Bose et al. 2011). Twinning occurs under tension along the $<0001>$ direction on the $\{1012\}$ and $\{1122\}$ planes. A majority of the basal poles in the pressure tubes are oriented in the circumferential direction and to some extent, in the radial direction. With majority of $\{0001\}$ poles aligned in the transverse direction, it requires the plastic flow to occur primarily by the more difficult $\{1011\}<1123>$ pyramidal slip (Bose et al. 2011)or by twinning(Kim 2008). Thus pyramidal slip and twinning is responsible for higher YS in the transverse specimen because the critical resolved shear stress (CRSS) for pyramidal slip and twinning are higher than that for slip.

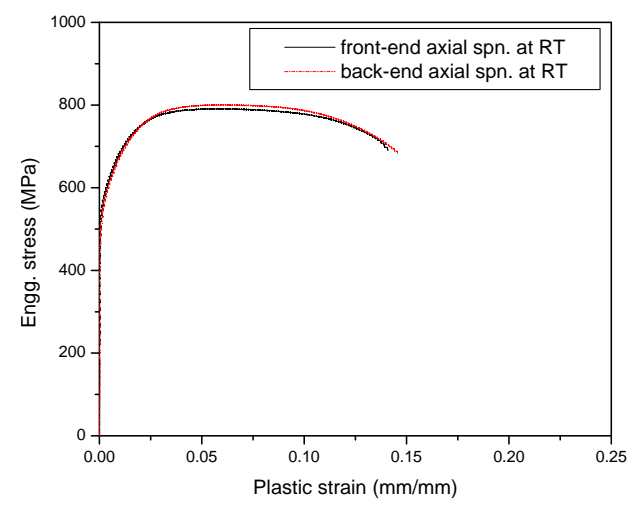

(a)

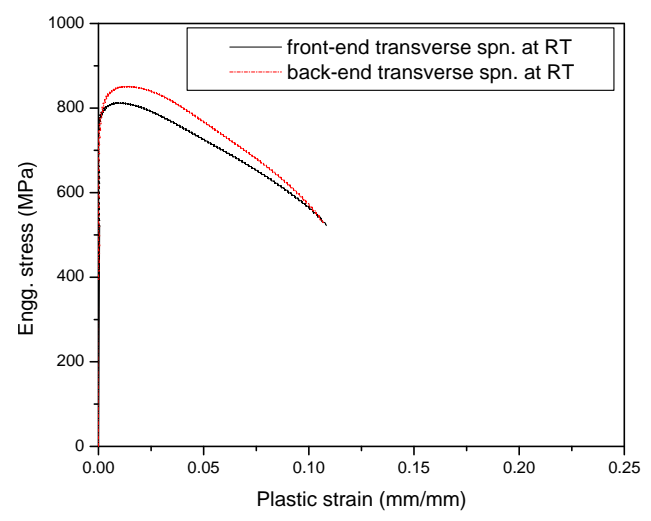

(b)

Fig. 3: Typical stress-strain plot obtained in testing of (a) axial specimen and (b) transverse specimen from front-end and back-end off-cut

Once yielding occurs by twinning, further deformation occurs primarily in the twinned regions that are now better aligned for slip. The deformation will then take place locally there, leading to localized deformation in the necked region (Kim 2008) as shown in fig. 4b showing failed transverse specimen. The axial specimens when loaded deform by slipping as the slip systems are better oriented in this orientation of specimen and the CRSS for slip is lower than that for twinning. This leads to lower YS in the axial specimen of the $\mathrm{Zr}-2.5 \mathrm{Nb}$ pressure tube. Slip fosters uniform deformation along the gauge section and it leads to greater extent of strain hardening. As compared to the localized deformation in 
transverse specimen, the axial specimens show more uniform deformation along the gauge length as shown in fig. 4a.

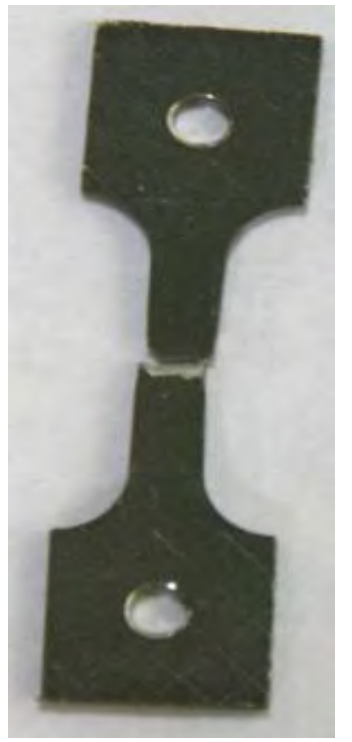

Fig. 4a: Tensile tested axial specimen

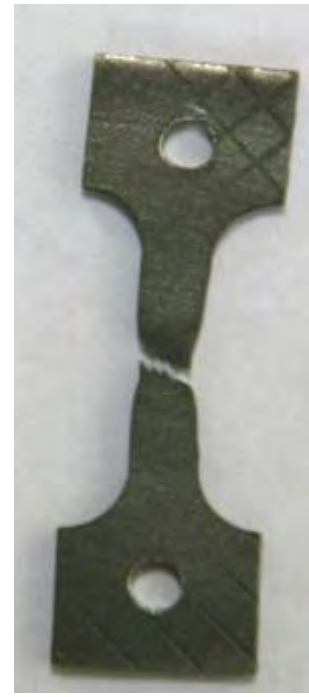

Fig. 4b: Tensile tested transverse specimen

\section{Double-Melted (DM) And Quadruple-Melted (QM) Pressure Tube Properties:}

Table 3 shows the mean value and standard deviation of the tensile properties of double-melted and quadruple melted pressure tube off-cuts. Normal distribution of tensile properties for double-melted and quadruple melted $\mathrm{Zr}-2.5 \mathrm{Nb}$ pressure tube off-cuts is shown in fig.5 and fig.6. It is clear from these table and figures that double-melted pressure tubes show wider scatter compared to the quadruple-melted pressure tubes. Double-melted pressure tubes have relatively higher strength and lower elongation compared to quadruple-melted pressure tubes in the longitudinal direction as seen in fig.5. Figure 6 shows that the transverse property is quite comparable for these two types of pressure tubes.

Table 3: Tensile properties of double-meted and quadruple-melted pressure tube off-cuts

\begin{tabular}{|c|c|c|c|c|c|c|c|c|}
\hline \multirow{2}{*}{$\begin{array}{c}\text { Tensile } \\
\text { properties }\end{array}$} & \multicolumn{4}{|c|}{ Double melted } & \multicolumn{4}{c|}{ Quadruple melted } \\
\cline { 2 - 9 } & \multicolumn{2}{|c|}{ Longitudinal } & \multicolumn{2}{c|}{ Transverse } & \multicolumn{2}{c|}{ Longitudinal } & \multicolumn{2}{c|}{ Transverse } \\
\cline { 2 - 9 } & Mean & Std. Dev. & Mean & Std. Dev. & Mean & Std. Dev. & Mean & Std. Dev. \\
\hline YS (MPa) & 618 & 29 & 793 & 77 & 583 & 23 & 780 & 29 \\
\hline UTS (MPa) & 803 & 43 & 833 & 68 & 792 & 26 & 836 & 28 \\
\hline UE (\%) & 5.7 & 0.62 & 2.5 & 0.62 & 6.4 & 0.35 & 2.14 & 0.24 \\
\hline TE (\%) & 14.0 & 2.29 & 12.5 & 1.65 & 16.0 & 1.59 & 12.3 & 1.87 \\
\hline
\end{tabular}




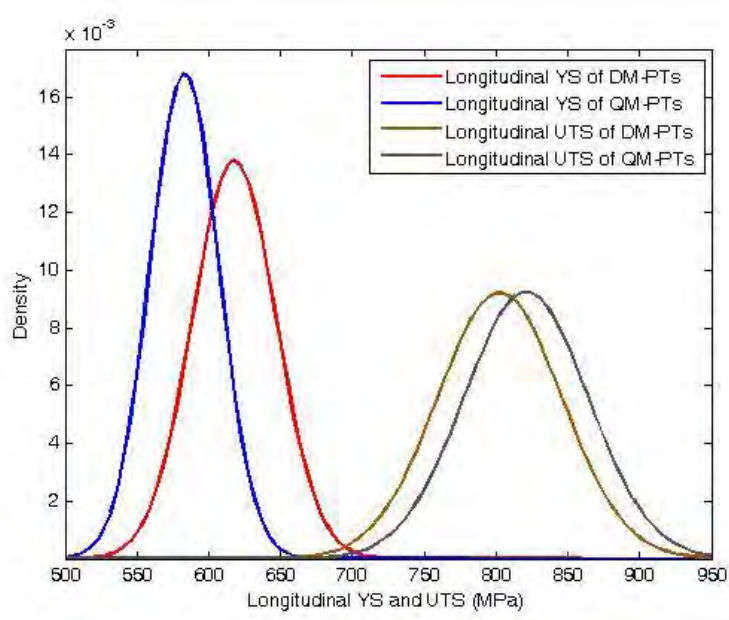

(a)

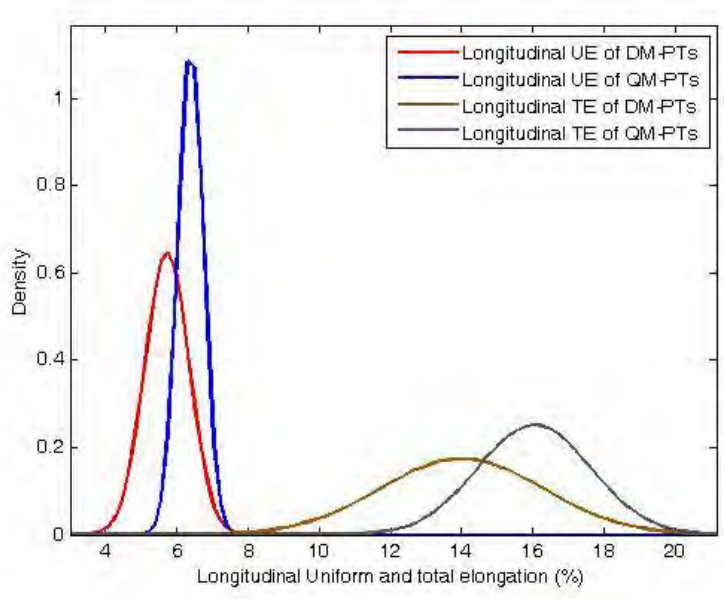

(b)

Fig.5: Distribution of (a) strength and (b) elongation properties in longitudinal direction for double-meted and quadruple-melted pressure tube off-cuts

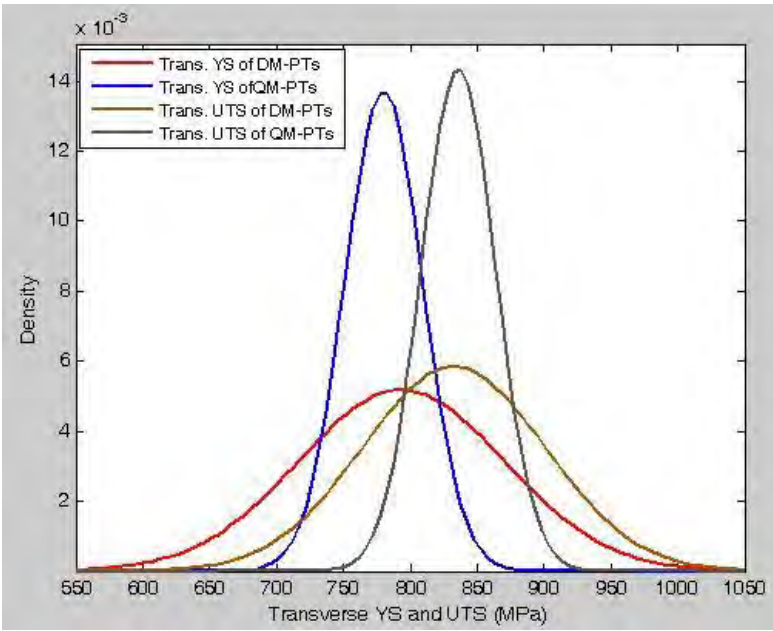

(a)

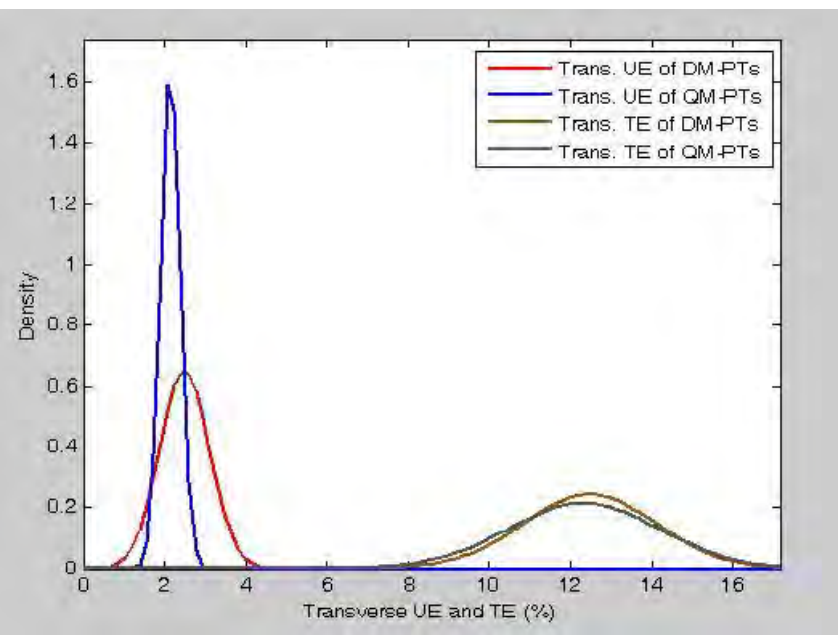

(b)

Fig.6: Distribution of (a) strength and (b) elongation properties in transverse direction for DM and QM pressure tube off-cuts

The standard pressure tube has the majority of basal poles in the transverse direction (Fleck et al. 1984, Christodoulou et al. 2000). The resolved fraction of basal plane normal in the axial, transverse and radial directions (fa, $\mathrm{ft}$ and $\mathrm{fr}$ ) and the dislocation density of pressure tubes as measured by X-ray line broadening for the DM and QM pressure tubes are shown in fig. 7. The higher strength in double-melted pressure tube may be partly due to higher dislocation density as the texture in double-melted and quadruple-melted are in close boundary as seen in fig. $7 \mathrm{a}$. 


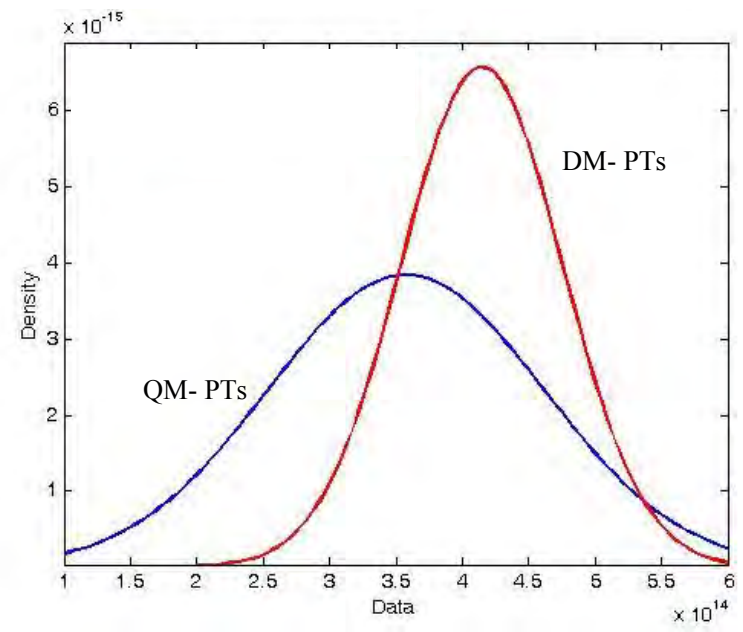

(a)

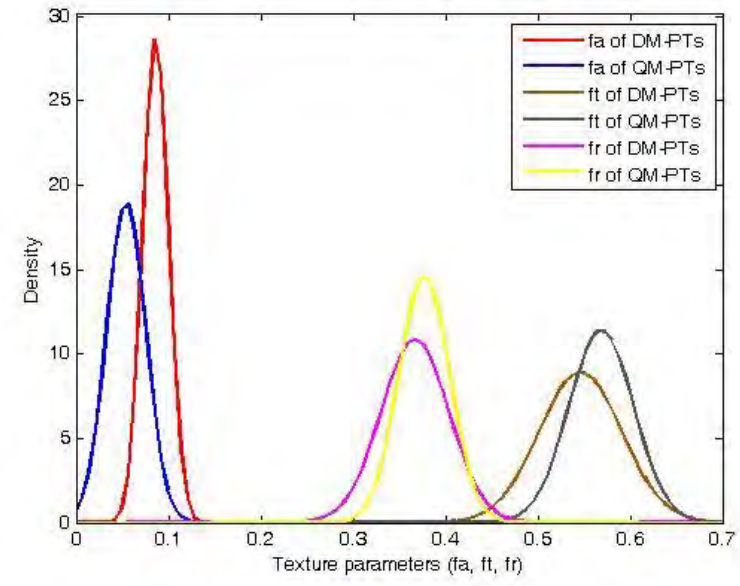

(b)

Fig.7: Distribution of (a) dislocation density and (b) texture in DM and QM pressure tube off-cuts

\section{Tube To Tube Variation In Tensile Properties For Front-End Of The QM Pressure Tubes}

Tube to tube variation in the axial and transverse tensile properties for the front-end of the quadruple melted PTs is shown in fig. 8. The mean and standard deviation (SD) of the tensile properties in longitudinal and transverse direction of pressure tube off-cuts is shown in table 4.

Table 4: Tensile properties in longitudinal and transverse direction of pressure tube

\begin{tabular}{|c|c|c|c|c|}
\hline \multirow{2}{*}{ Tensile properties } & \multicolumn{2}{|c|}{ Longitudinal orientation } & \multicolumn{2}{c|}{ Transverse orientation } \\
\cline { 2 - 5 } & Mean & Std. Dev. & Mean & Std. Dev. \\
\hline YS (MPa) & 575 & 26 & 774 & 44 \\
\hline UTS (MPa) & 787 & 33 & 831 & 37 \\
\hline UE (\%) & 6.5 & 0.34 & 2.0 & 0.56 \\
\hline TE (\%) & 15.8 & 1.97 & 13.2 & 1.6 \\
\hline
\end{tabular}

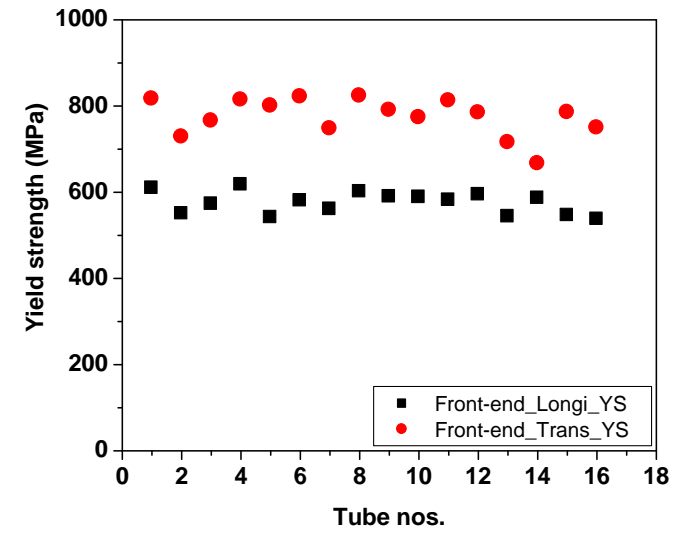

(a)

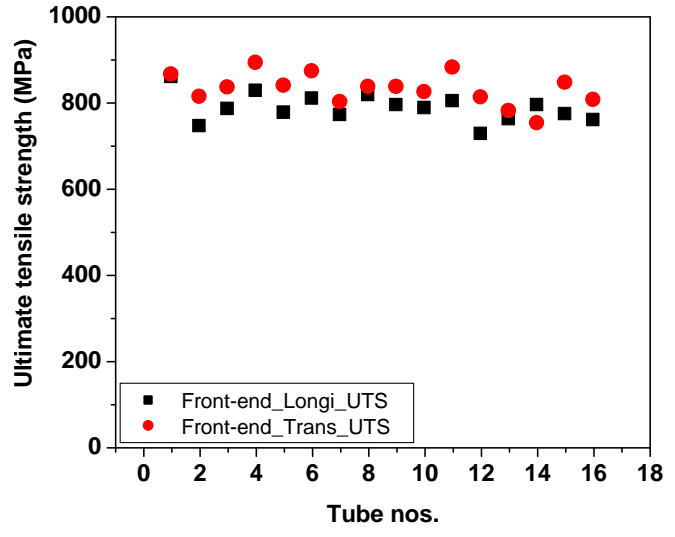

(b) 


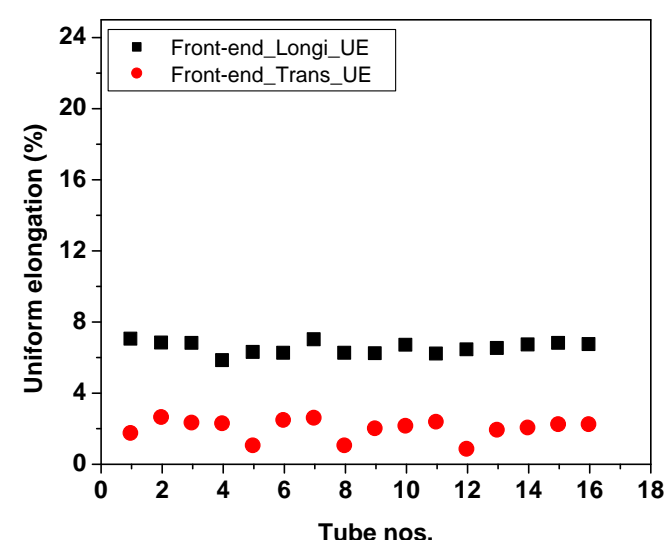

(c)

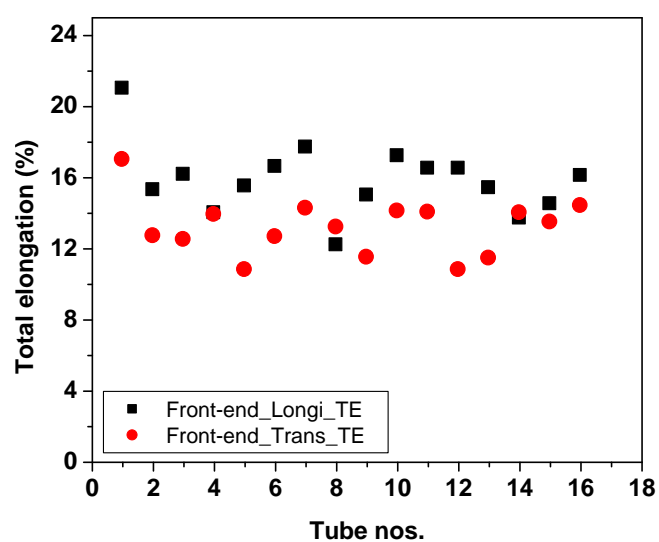

(d)

Fig.8: Scatter in tensile strength $(\mathrm{a} \& \mathrm{~b})$ and elongation $(\mathrm{c} \& \mathrm{~d})$ properties in longitudinal and transverse direction for the pressure tubes

\section{Scatter In Tensile Properties For Front-End And Back-End Of Quadruple-Melted Pressure Tubes}

Extrusion temperature variation between the leading and the trailing ends of the blank affects microstructure and therefore mechanical properties and flow behavior vary along the length of the pressure tube. The grain size varies along the length of the tube because the tubes cool during the extrusion process [d]. Back-end of the tube has a smaller $\alpha$-grain size and a higher dislocation density than the front-end of the tube, and these result in higher tensile strength at the back-end than the frontend.

The statistical variation in tensile property for the front-end and back-end of the quadruple-melted pressure tubes is shown by box-plot in fig. 9 \& fig.10. For the quadruple-melted pressure tubes studied in the present case did not show much difference between front-end and back-end off-cuts at room temperature except for total elongation in the transverse direction as seen in fig. 9 and fig. 10 represented in box-plots. Total elongation in the transverse direction is lower for the back-end off-cuts compared to the front-end off-cuts. It is also clear from the figures that the scatter band is relatively higher for frontend off-cuts compared to the back-end off-cuts.

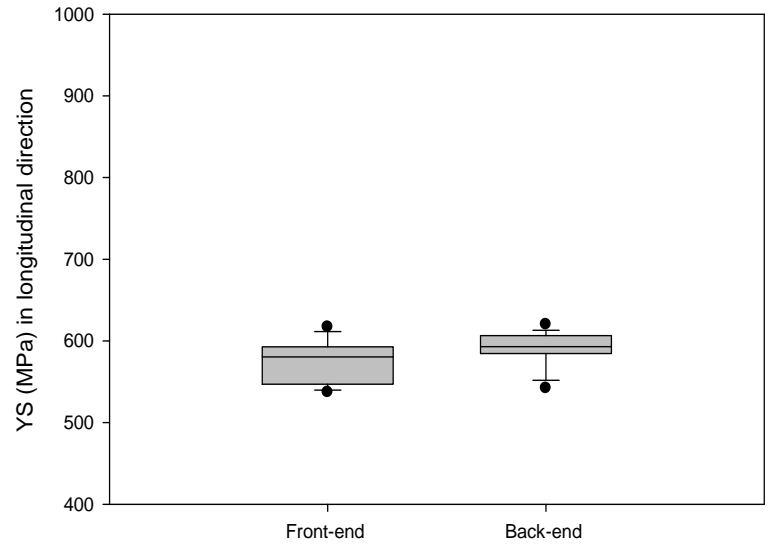

(a)

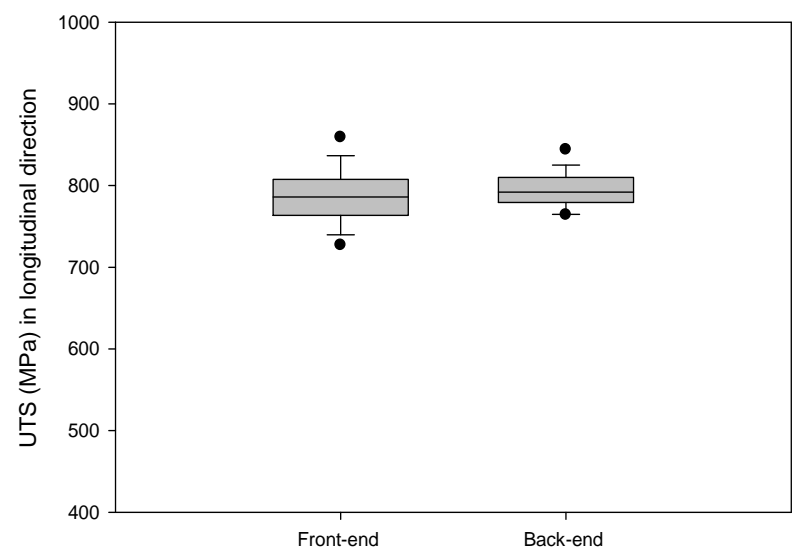

(b) 


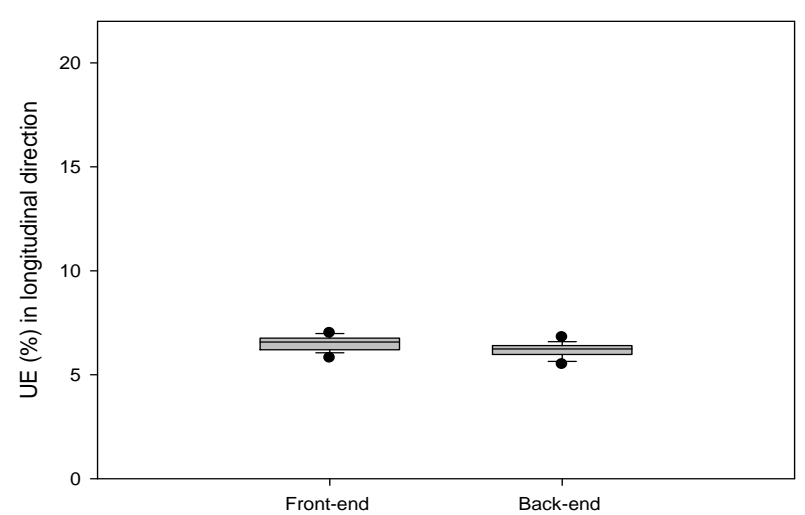

(c)

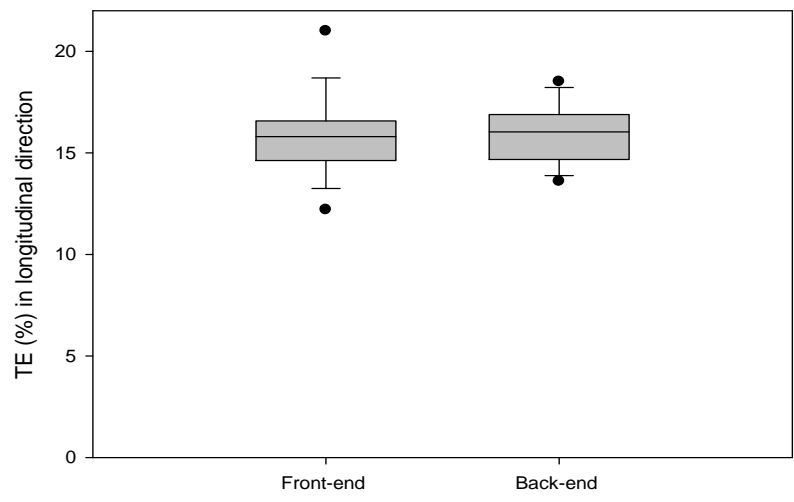

(d)

Fig.9: Box plot of strength ( $\mathrm{a} \& \mathrm{~b}$ ) and elongation (c \& d) in axial direction of front-end and back-end pressure tube off-cuts

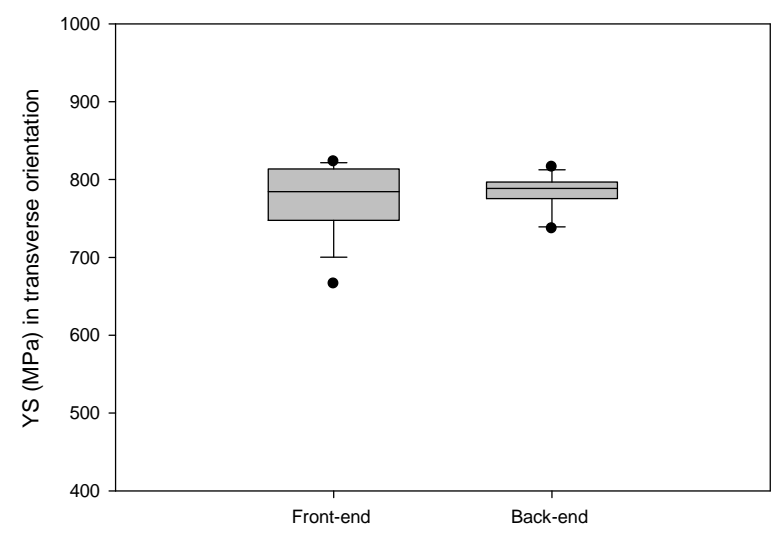

(a)

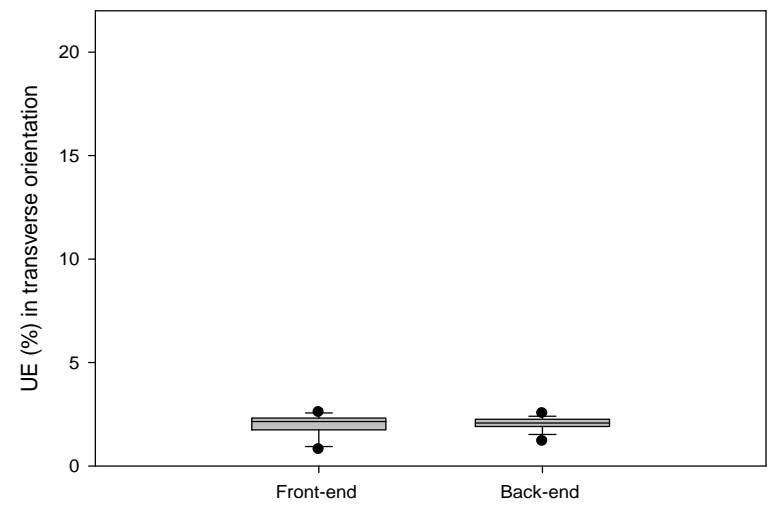

(c)

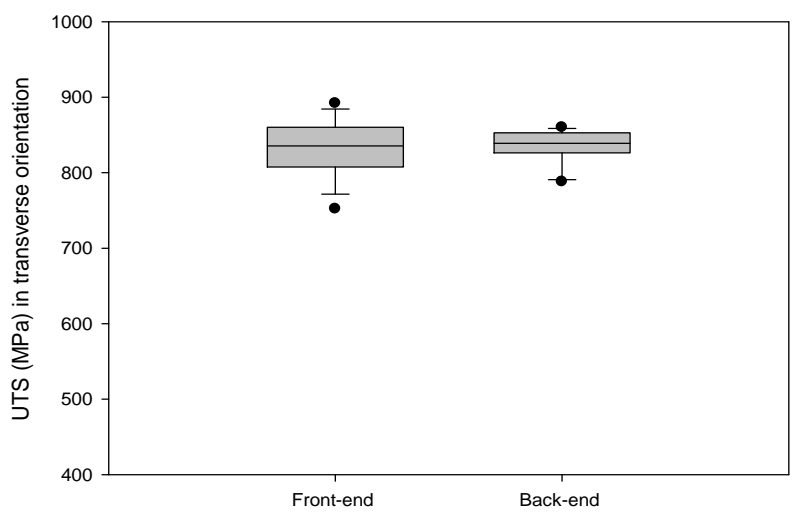

(b)

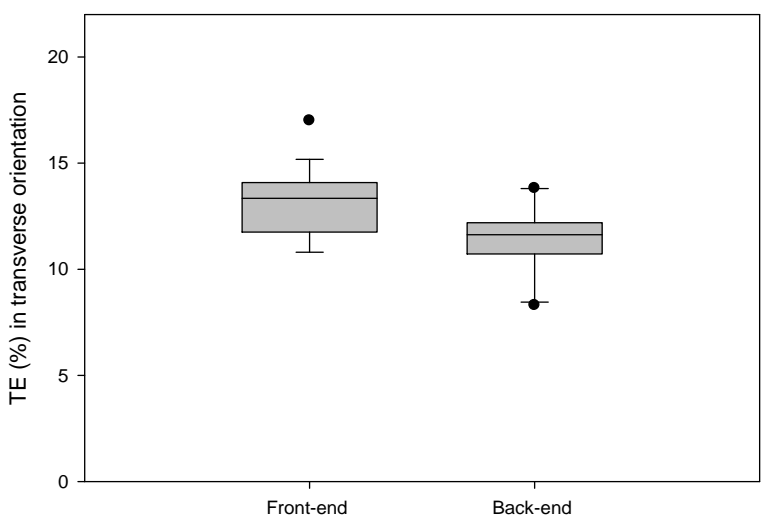

(d)

Fig.10: Box plot of elongation in transverse direction of front-end and back-end pressure tube off-cuts 


\section{CONCLUSIONS}

Tension tests have been done on specimens of both axial and transverse orientation and from both front-end and back-end off-cuts of sixteen pressure tubes. The tensile properties have been evaluated at room temperature using miniature flat tensile specimens.

In general the transverse specimens showed higher yield strength (YS) and ultimate tensile strength (UTS) compared to the longitudinal specimens. Transverse specimens showed less strain hardening compared to the longitudinal specimens. The axial specimens showed higher uniform (UE) and total elongation (TE) compared to the transverse specimens.

Not much variation was found between front-end and back-end of the pressure tubes.

Double-melted pressure tubes showed relatively higher strength and lower elongation and larger standard deviation compared to the quadruple melted pressure tubes.

\section{ACKNOWLEDGEMENT}

The authors wish to acknowledge Nuclear Power Corporation of India Limited (NPCIL), India for providing the off-cut material for evaluation of mechanical properties. The effort of Shri H.N. Tripathy is also acknowledged for his support in carrying out the tests.

\section{REFERENCES}

Bose, B. and Klassen, R. J. (2011). "Temperature dependence of the anisotropic deformation of Zr-2.5Nb pressure tube material during micro-indentation", Journal of Nuclear Materials, 419, 235-240.

Christodoulou, N., Turner, P. A., Ho, E. T. C., Chow, C. K. and Levi, M. R. (2000). "Anisotropy of yielding in a $\mathrm{Zr}-2.5 \mathrm{Nb}$ pressure tube material", Metallurgical and materials transactions A, 31A, 409-420.

Davies, P. H., Aitchison, I., Himbeault, D. D., Jarvine, A. K. and Watters, J. F. (1995). "On the fracture of cold-worked $\mathrm{Zr}-2.5 \mathrm{Nb}$ pressure tubes fabricated from $100 \%$ recycled material", Fatigue and fracture of engineering materials and structures, 18(7/8), 789-800.

Dureja, A. K., Sinha, S. K., Srivastava, A., Sinha, R. K., Chakravartty, J. K., Seshu, P. and Pawaskar, D. N. (2011). "Flow behavior of autoclaved, $20 \%$ cold worked, $\mathrm{Zr}-2.5 \mathrm{Nb}$ alloy pressure tube material in the temperature range of room temperature to $800^{\circ} \mathrm{C}$ ", Journal of Nuclear Materials, 412, 22-29.

Fleck, R. G., Price, E. G. and Cheadle, B. A. (1984). "Pressure tube development for CANDU reactors", Zirconium in the Nuclear Industry: Sixth International Symposium, ASTM STP 824, 88-105.

Ganguly, C. (2002). "Advances in Zirconium technology for nuclear reactor application", Proc. Of the Symposium Zirconium-2002, ZIRC-2002, Mumbai, India, 1-27.

Kapoor, K., Murlidharan, K. and Saratchandran, N. (1999). "Microstructure evolution and tensile properties of $\mathrm{Zr}-2.5 \mathrm{wt} \% \mathrm{Nb}$ pressure tubes processed from billets with different microstructures", Journal of materials engineering and performance, 8(1), 61-67.

Kim, Y.S. (2008). "Role of twinning and slip in deformation of a $\mathrm{Zr}-2.5 \mathrm{Nb}$ tube", Journal of ASTM International, 5(6).

Rodgers, D. K., Coleman, C. E., Griffith, M., Bickel, G. A., Theaker, J. R., Muir, I., Bahurmuz, A. A., St. Lawrence, S. and Levi M. R. (2008), "In-reactor performance of pressure tubes in CANDU reactors", Journal of Nuclear Materials, 383, 22-27.

Shewfelt, R.S. W. (1984). "The anisotropic deformation of $\mathrm{Zr}-2.5 \mathrm{wt} \% \mathrm{Nb}$ CANDU pressure tubes between 20 and $700^{\circ} \mathrm{C}$ ", Canadian metallurgical quarterly, 23(4), 441-445.

Singh, R. N. and De, P. K. (2002). "Hydrogen related problems in Zirconium alloy core components in PHWR", Proc. Of the Symposium Zirconium-2002, ZIRC-2002, Mumbai, India, 103-108.

Srivastava, D., Dey, G. K. and Banerjee, S. (1995). "Evolution of microstructure during fabrication of Zr2.5 wt pet Nb alloy pressure tubes", Metallurgical and materials transactions A, 26A, 2707-2718. 